\title{
TRABALHO EM EQUIPE E TRABALHO EM GRUPO NO PROGRAMA DE SAÚDE DA FAMÍLIA
}

\author{
Maria Helena Trench Ciampone ${ }^{1}$ \\ Marina Peduzzi ${ }^{2}$
}

\section{INTRODUÇÃO}

Nós, autoras deste trabalho, vimos atuando ao longo de nossa formação profissional como docentes e pesquisadoras na área de recursos humanos e gerenciamento de serviços de saúde e, nesse contexto, estamos envolvidas, mais recentemente, em diferentes âmbitos de delineamento e execução das propostas de capacitação de equipes para atuarem no Programa de Saúde da Família. Nesse sentido, temos refletido sobre o escopo Os acordos por meio dos quais se configura o projeto comum, requer que os profissionais possam se questionar também no plano técnico, ou seja, quanto às intervenções que executam ou julgam necessárias.

da proposta e a forma como tem sido operacionalizada, cabendo-nos, no presente momento, levantar alguns questionamentos e pontos para discussão no que se refere às estratégias de trabalho em equipe e de trabalho em grupo, segundo os estudos e pesquisas que temos desenvolvido sobre a temática (Peduzzi, 1998, Ciampone, 1998).

No que se refere à organização institucional ou modelo assistencial, vários estudos desenvolvidos no Brasil, mostram a hegemonia da abordagem clínica centrada no cuidado individual e na assistência médica, objetivando a reinstauração de uma dada normatividade biológica. Estes estudos analisam e assinalam a necessidade de superação desse modelo assistencial pela articulação de intervenções de diferentes naturezas, com destaque para a participação dos sujeitos - população, usuária dos serviços ou não, e agentes do trabalho. (Schraiber, 1990, Almeida, 1991, Merhy, 1992, Campos, 1992; Mendes, 1994)

Esta reflexão ocorre integrada à um movimento de natureza política e de intervenção nos serviços de saúde, que busca viabilizar a transformação do modelo de atenção. Neste sentido, a VIII Conferência Nacional de Saúde representou um momento de síntese, formulando, com legitimidade, um projeto de saúde para o país com base nos princípios da universalidade, integralidade, equidade, descentralização, hierarquização e participação popular.

O Programa de Saúde da Família tem sua origem neste cenário e coloca-se como estratégia de reestruturação do modelo assistencial em conformidade com o ideário ético-político e técnico do Sistema Único de Saúde (Conh; Elias, 1996). As diretrizes operacionais do Programa ressaltam a adscrição da clientela, a integração dos níveis de atenção à saúde, o planejamento local e regional com base no pensamento estratégico, o trabalho em equipe, a ação intersetorial e o controle social (BRASIL, 1996). Assim, o PSF elege como ponto central o estabelecimento de vínculos e a criação de laços de compromisso e de co-responsabilidade entre os profissionais de saúde e a população.

À medida que o PSF busca constituir-se como um modelo de atenção que contempla as múltiplas dimensões das necessidades de saúde na sua dupla face - individual e coletiva, propõe mudanças no objeto de atenção, na forma de atuação profissional e na organização dos serviços. A ampliação do objeto de atenção está presente no deslocamento proposto do indivíduo para a família e

1 Enfermeira, Doutora em Psicologia Social, Livre-Docente junto ao Departamento de Orientação Profissional da Escola de Enfermagem da USP.

2. Enfermeira, Doutora em saúde Coletiva, Professor doutor junto ao Departamento de Orientação Profissional da Escola de Enfermagem da USP. 
do interior dos serviços para o espaço/domicílio, na esfera da vida social. Esta ampliação do objeto de intervenção para além do âmbito individual e clínico, faz necessária a ação multiprofissional, presente na proposta do trabalho em equipe, e a modalidade de atenção à grupos, presente na proposta trabalho em grupos familiares.

Para tanto, há que se construir um novo pensar e fazer nessa prática que requer alta complexidade de saberes, de desenvolvimento de habilidades e de mudanças de atitudes, por parte de toda a equipe, o que se constitui em verdadeiro desafio.

\section{CONCEITUANDO TRABALHO EM EQUIPE E TRABALHO EM GRUPO}

No senso comum, um grupo é constituído por um conjunto de pessoas que se reúnem em um determinado espaço de tempo e lugar, tendo um objetivo em comum. Contudo essa representação deixa de contemplar algo que é essencial na constituição de um grupo, que é o que o diferencia de uma serialidade, no sentido de que cada indivíduo numa série seria equivalente ao outro e sem diferenciação. Numa série pressupõe-se uma não relação entre as pessoas, um não vinculo. Pois bem, quando nos referimos a um grupo, no contexto deste trabalho, estamos adotando a concepção de grupo advinda da psicologia social, na qual os estudiosos no campo grupal, explicitam que o que diferencia um grupo de uma série é justamente "estar em interação e partilhar normas na realização de uma tarefa". Segundo Pichon (1982), é justamente a concepção de vínculo que diferencia a sociabilidade por interação no campo grupal.

As relações intersubjetivas no campo grupal são dirigidas e se estabelecem sobre a base de necessidades, que é o fundamento motivacional do vínculo. Todo vínculo, assim entendido, implica a existência de um emissor, um receptor, uma codificação e decodificação de mensagens, isto é, pressupõe um processo de comunicação entre seus integrantes. Nesse interatuar dá-se a internalização dessa estrutura relacional, que adquire uma dimensão intra-subjetiva que constitui-se no vínculo. Isto posto, postula-se que em um grupo, existe a alteridade, ou seja, aceitação do outro enquanto sujeito pensante e autônomo, por cada um dos atores sociais que mantêm entre si vínculos e relações afetivas de diversas naturezas.

Já na literatura sobre equipe de saúde observamos que são raras as definições ou conceitos sobre o tema. Tanto na produção teórica, quanto na prática em serviços, predomina a concepção de equipe do senso comum, onde a equipe é representada como o conjunto de profissionais em situação comum de trabalho. Se assim fosse, todo conjunto de trabalhadores configuraria equipe e todo trabaIho seria trabalho em equipe. No entanto, utilizamos a denominação "equipe de saúde" e "trabalho em equipe" para algumas situações específicas. Cabe, portanto, indagar quais as características que nos permitem identificar esta específica modalidade de trabalho coletivo?

Em primeiro lugar, destacamos que a denominação "equipe", no processo de produção em saúde, sempre fará referência a uma situação de "trabalho" e que este refere-se à obtenção de bens ou produtos para a atenção às necessidades humanas. Portanto, em primeira instância, cabe a equipe a responsabilidade pela obtenção de resultados que expressem a finalidade do trabalho que produz.

Convencionou-se distinguir por completo a esfera do trabalho e a esfera das relações interpessoais, no entanto, o trabalho é permeado pela comunicação e interação do agentes. Segundo estudo desenvolvido por Peduzzi (1998), com base no processo de trabalho em saúde e na teoria do agir comunicativo de Habermas $(1989,1994)$, é justamente a relação recíproca entre estas duas dimensões complementares - trabalho e interação - que caracteriza o que denominamos de trabalho em equipe. Assim, o trabalho em equipe constituiria uma prática em que a comunicação entre os profissionais faz parte do exercício cotidiano do trabalho e os agentes operam a articulação das intervenções técnicas por meio da mediação simbólica da linguagem. Neste sentido, há que se considerar duas dimensões inerentes ao trabalho em equipe: a articulação das ações e a interação dos profissionais.

Quando a equipe é multiprofissional, a articulação refere-se a recomposição de processos de trabalho distintos e, portanto, a consideração das conexões e interfaces existentes entre as interven- 
ções técnicas peculiares de cada área profissional, bem como a preservação das respectivas especificidades. A integração da equipe demanda, simultaneamente, preservar as diferenças técnicas e flexibilizar as fronteiras entre as áreas profissionais. A complexa conjugação entre especificidade, flexibilidade e articulação, torna-se ainda mais desafiadora a medida que, para além das diferenças técnicas entre as distintas áreas profissionais, expressa desigualdade entre os trabalhos especializados. Ou seja, evidencia a existência de valores sociais hierarquizando e disciplinando relações de subordinação entre as diferentes áreas de trabalho e seus respectivos agentes.

A interação é, aqui, entendida como uma prática comunicativa por meio da qual os envolvidos colocam-se de acordo quanto a um projeto comum. Os sujeitos constróem consensos sobre um plano de ação por meio de uma modalidade de comunicação dialógica - de dupla mão, em que os envolvidos partilham os enunciados que proferem e as normas e valores que subjazem esses proferimentos. Ou seja, colocam-se de acordo quanto ao que dizem e aos valores pressupostos compartilhando valores éticos (Habermas, 1989, 1994).

\section{A INTERSEÇÃO ENTRE TRABALHO EM EQUIPE E TRABALHO EM GRUPO}

As concepções, acima referidas, sobre equipe e grupo, permitem-nos tanto identificar aspectos em que ambos os conceitos aproximam-se, quanto aspectos em que se distinguem. Como podemos observar, a interação destaca-se como dimensão intrínseca, seja para o trabalho em equipe, seja para o trabalho em grupo. No entanto, para o trabalho em equipe a centralidade está na obtenção de resultados, ou seja, na atenção integral às necessidades de saúde da clientela, o que pode ser incrementado em qualidade a medida que a comunicação em busca de consensos, entre os profissionais, integre o trabalho cotidiano. E para o trabalho em grupo a centralidade está na dinâmica das inter-relações e no vínculo entre os integrantes do grupo, que potencializa a realização da tarefa.

Caberia ao grupo de profissionais, o desenvolvimento da potencialidade para trabalhar tanto em grupo, como em equipe. Segundo Pichon (1982), "trabalhar como um grupo operativo, contempla tornar manifesto os conteúdos implícitos do grupo (equipe e grupo familiar) relacionados com a tarefa proposta. Isto implica conceber que os implícitos em qualquer campo grupal, permanecendo como tal, significam obstáculos à aprendizagem. Assim a aprendizagem da coordenação de grupos implica em operar verbalmente através da comunicação com o grupo assinalando e interpretando o que se passa no grupo quando este se encontra em uma situação conflitiva, dilemática, e não pode seguir adiante sozinho no seu trabalho. Na medida em que a confrontação entre o âmbito do intersubjetivo e o âmbito do intra-subjetivo seja dialética ou dilemática, é que a aprendizagem será facilitada ou obstaculizada. Ou seja, dependerá de que o processo de interação funcione como um círculo aberto, com uma trajetória em espiral, ou como um círculo fechado, viciado pela estereotipia. O papel do coordenador de grupo, que deve ser desenvolvido e potencializado em todos os integrantes da equipe pressupõe a facilitação desse processo de interação e aprendizagem de desenvolvimento de novas condutas e papéis, de modo ativo e participativo.

Assim, cabe-nos reconhecer que, a maior parte da nossa formação como profissionais de saúde ainda está pautada no modelo biomédico, configurando uma cisão entre o biológico e o psicossocial e, portanto, pouco nos instrumentaliza para a atuação na esfera da interação, seja com o usuário, seja com os demais profissionais.

Nessa perspectiva, não temos internalizada a experiência da coordenação de grupos. Em geral, somos também condicionados a acreditar que o técnico é o dono da verdade no sentido de saber o que é o melhor para o outro, o que fazer e como fazer, desconsiderando, muitas vezes a cultura, crenças e valores que determinam uma dada forma de ser. Por conta disso, acabamos estendendo essa "verdade", esse saber, às relações interpessoais no trabalho, que longe de ser um trabalho em equipe, acaba por se tornar competitivo, ao invés de ser cooperativo. Por isso, Pichon argumenta que estar em grupo operativo implica em aprender a aprender e isso vale também para aprendizagem do que é constituir uma equipe de trabalho (Ciampone, 1998, p. 132).

Tal construção ocorre a medida em que os profissionais tomem a comunicação entre eles como dimensão intrínseca ao trabalho, considerando efetivamente a prática dos demais como 
interdependente e complementar a sua e a negociação como via de acesso a um projeto comum de trabalho. Os acordos por meio dos quais se configura o projeto comum, requer que os profissionais possam se questionar também no plano técnico, ou seja, quanto às intervenções que executam ou julgam necessárias. Ou seja, os agentes precisam colocar-se de acordo quanto às ações específicas de cada área e a conexão entre elas.

\section{CONSIDERAÇÕES FINAIS}

Buscamos ressaltar o caráter potencializador que a proposta de intervenção centrada no grupo familiar contempla, por seu caráter oportuno quanto à possibilidade de constituir-se em recurso para o "empoderamento dos sujeitos", tanto os profissionais de saúde, quanto os usuários e familiares, frente à dura realidade a ser enfrentada. Tanto a proposta de trabalho em equipe, como a perspectiva do grupo familiar como objeto da intervenção, propiciam o que (Merhy, Chakkour, citados por Merhy, Onocko, 1997) denomina de espaços intercessores, referindo-se a espaços onde há possibilidade de criar-se instituintes, isto é, criar-se espaços potencialmente transformadores daquilo que está determinado à priori (instituído), como modos de ação e reação.

Corroborando com a afirmação acima, um recente trabalho realizado por Fortuna (1999) que tem como foco o trabalho em equipe produzindo-se e reproduzindo-se em subjetividades, chama a atenção para a rede de micropoderes presentes nas unidades básicas de saúde que atravessam a rede de relações podendo se fazer potencialmente transversalizadoras. Neste estudo, a autora partindo do entendimento de trabalho em equipe como um processo de inter-relação, analisa as relações entre os trabalhadores enquanto processos grupais, chamando a atenção para os possíveis espaços de transformação/transversalidade que se configuram como possibilidades para o trabalho em equipe. Contudo chamamos a atenção para as habilidades relacionais tomadas como ferramentas essenciais da proposta de transformação de modelos assistências, compreendidas no projeto da Saúde da Família.

Temos claro que os conceitos e a ética presentes em cada uso ou apropriação do conhecimento sobre o trabalho em equipe e o trabalho em grupo podem suscitar, ou não, a denúncia de violência simbólica que se impõe em todo modelo, norma, verdade e todas as naturalizações possíveis implicadas no trabalho em instituições.

É nossa intenção abrir o diálogo, buscar a compreensão, compartilhar preocupações e também oportunidades. Não nos cabe definir como trabalhar em equipe, como operar em um grupo. Pensamos, que nesse momento de construção e desafios, a cada um cabe fazer pronunciamentos interrogando a própria leitura da realidade, que é complexa e multifacetada, bem como, interrogar os próprios saberes e a própria experiência, produzindo outras discussões. O tempo presente urge por esforços cooperativos, pela soma, e não por divisão ou isolamento na produção da alternativas!

\section{REFERÊNCIAS BIBLIOGRÁFICAS}

ALMEIDA, M.C.P. O trabalho de enfermagem e sua articulação com o processo de trabalho em saúde coletiva: rede básica de saúde. Ribeirão Preto, 1991. Tese (Livre-Docência) - Escola de Enfermagem de Ribeirão Preto, Universidade de São Paulo.

BRASIL. Ministério da Saúde. Saúde da família: uma estratégia de organização dos serviços de saúde. Brasília-DF, 1996.

CAMPOS, G.W. de S. Reforma da reforma: repensando a saúde. São Paulo: Hucitec, 1992.

CIAMPONE, M.H.T. Grupo operativo: construindo as bases para o ensino e a prática na enfermagem. São Paulo, 1998. Tese (Livre-Docência) - Escola de Enfermagem, Universidade de São Paulo.

COHN, A; ELIAS, P.E. Saúde no Brasil: políticas e organização de serviços. São Paulo: Cortez, 1996. 
FORTUNA, C.M. O trabalho de equipe numa unidade básica de saúde: produzindo e reproduzindo-se em subjetividades: em busca do desejo, do devir e de singularidades. Ribeirão Preto, 1999. Dissertação (Mestrado) - Escola de Enfermagem de Ribeirão Preto, Universidade de São Paulo.

Técnica e ciência como ideologia. Lisboa: Edições 70, 1994.

HABERMAS, J. Consciência moral e o agir comunicativo. Rio de Janeiro: Tempo Brasileiro, 1989.

MENDES, E.V. Distrito sanitário: o processo social de mudança das práticas sanitárias do Sistema Único de Saúde. São Paulo: Hucitec, 1994.

MERHY, E.E. A saúde pública como política. São Paulo: Hucitec, 1992.

MERHY, E.E.; CHAKKOUR, M. Em busca de ferramentas analisadoras das tecnologias em saúde: a informação e o dia a dia de um serviço, interrogando e gerindo o trabalho em saúde. In: MERHY, E.E.; ONOCKO, R. (Org.) Agir em saúde: um desafio para o público. São Paulo: Hucitec, 1997.

PEDUZZI, M. Equipe multiprofissional de saúde: a interface entre trabalho e interação. Campinas, 1998. Tese (Doutorado) - Faculdade de Ciências Médicas, Universidade Estadual de Campinas.

PICHON RIVIĖRE, E. Processo grupal. São Paulo: Martins fontes, 1982.

SCHRAIBER, L. (Org.). Programação em saúde hoje. São Paulo: Hucitec, 1990. 